\title{
Human capital development in the digitalization risk management process
}

\author{
Tatiana Kharlamova \\ Graduate School of Business and Management \\ Peter the Great St.Petersburg Polytechnic University \\ St. Petersburg, Russia \\ Kharlamova_t@list.ru
}

\author{
Andrey Kharlamov \\ Chair of General Economic Theory and the History of Economic \\ Thought \\ St.Petersburg State University of Economics \\ St. Petersburg, Russia \\ Kharlamov_2000@list.ru
}

\begin{abstract}
The article considers the problem of improvement of the human capital of companies engaged in the digitalization of production and management processes. Along with serious technological and communicative advantages, the digitalization creates new risks, as well as transforms existing ones. This implies effective risk management based on selftraining of employees, increasing their responsibility and formation of new knowledge and competencies. Thus, the process of digitalization forms the necessary foundation for strengthening the creative component of labor and the development of human capital. The authors identified the basis for the development of human capitalë in the course of digital risk management, and proposed areas of management impact on this process. They are presented in the form of a sequence of managerial actions to work with information in the field of digital risks and the procedure for evaluating the effectiveness of working with digital risks, based on the cost grouping. In general, these proposals contribute to the formation of a new, effective model of organizational behavior of employees and the development of their human capital.
\end{abstract}

Keywords - human capital, digitalization, risk, management, development

\section{INTRODUCTION}

In the modern conditions of globalization and the rapid development of information technology, digitalization is considered as a fundamental tool that ensures the effectiveness of companies and increasing their competitiveness. Existing trends reflect the growing interest in innovative technologies and new management practices that are relevant to modern digital trends in the development of the economy and society. Digital technologies are constantly being improved, especially in the field of application of automated information management systems, block chain, development of robotics, personalized services and means of communication.

At the same time, the emergence of new opportunities in this area is often associated with the enhancement of existing and the emergence of new risks. This requires the management of modern companies to search for new, effective ways to modernize the risk management system accompanying the digital transformation processes. These processes, representing not only theoretical, but also practical interest, require detailed study today.

Analysis of available scientific publications shows that research in recent years, mainly conducted in areas such as:

Theoretical foundations of formation, development and management of human capital $[1,2,3]$;
The role of the state in the development of human capital and the problems of working time $[4,5,6]$;

Features of the formation of human capital in a digital economy and the use of its capabilities in business [7, 8, 9, $10]$;

The role of education in the development of human capital and the place of the knowledge economy as a generator of this process $[11,12,13,14]$;

The level of human capital and its impact on income generation, taking into account cross-country differences $[15,16,17,18,19]$;

The relationship between the emergence of digital risks and the activities of personnel [20,21].

As evidenced by the results of modern research in the above areas, the role of the digital factor is constantly increasing, both at the stage of identifying the risk and at all subsequent stages, until its minimization or elimination. At the same time, today it is impossible to talk about the full security of digital systems with the necessary managerial tools. Obviously, there will always be a lag, because the pace of development of information technology today is ahead of the pace of development of all other spheres of human activity. In these conditions, the emergence of new information technologies and digital managerial practices can carry not only competitive advantages, but also numerous risks. This could make the participants in business activities more vulnerable to competitors or third parties using these technologies for personal gain (for example, by organizing cyber-attacks or various fraudulent schemes).

Management activities in this area should be aimed at solving a multi-component task, including economic, informational, technological, communication, as well as personal and motivational aspects. These may also include issues related to the intensive use and improvement of human capital, which have received increasing attention in recent years in the global scientific community.

In accordance with current global trends, human capital is the most important resource of high-tech companies and companies engaged in digital transformation. This updates research on the improvement of the human capital of modern companies, both in traditional and new areas of business, including risk management of digitalization.

The hypothesis of this article is the next: the risk management of digitalization ensures the desire of employees to realize their existing innovative and creative 
potential, as well as to increase the knowledge, skills and competencies that improve the company's human capital.

The aim of the study is to substantiate the modern approach to the improvement of human capital in the risk management process in terms of digitalization.

In accordance with a determined aim, the following research tasks can be presented:

- to identify the basis for effective organization of work with personnel engaged in managing digital risks and their relationship with the improvement of the company's human capital;

- to present a sequence of managerial actions on working with information in the field of digital risks, focused on improvement of human capital;

- to suggest some ways to assess the effectiveness of working with digital risks.

\section{MATERIALS AND METHODS}

Today, special attention is paid to the development of human capital, based on the need to improve the efficiency of each business entity, from the household to the state. This has a decisive impact on the functioning of the entire national economy, ensuring the position of the country in various international ratings. In this regard, the comparison of international ratings of various countries in such indicators as the development of human capital and the development of innovations is of interest (Table 1).

When ranking countries we will use the assessments conducted by the World Economic Forum in collaboration with Harvard University and the International Company Mercer Human Resource Consulting [22] and the International Business School of INSEAD (Cornell University) with the World Intellectual Property Organization [23].

In general, here we can see a similarity of the analyzed indicators: if a country occupies high positions in the field of human capital development, then it ensures comparable positions for itself in the field of innovative development. The existing exceptions (primarily Norway) are connected with the peculiarities of the economic system and the development strategy of a particular country, which doesn't contradict our conclusion about the high level of interconnection of the indicators under consideration.

It should be noted that the features of the functioning of the national economic system imprint both on the work of companies and on the specifics of the human capital of workers, especially in conditions of increasing risks.

Today, we are witnessing an increase in the impact of risks on all areas of a company's activity; however, the most tangible risks are closely associated with a level of human capital development and innovation. Here, first of all, we are talking about digital risks.

The principal feature of working with them is the amount of information to which each employee has access, depending on his status and belonging to one or another hierarchical level of management. This actualizes such a problem as trust and dispensing of information, especially the information, the leakage of which can lead to serious problems, up to the loss of competitive positions and the bankruptcy of the company. Consequently, the entire amount of information must be distributed among employees; their contacts with each other should be regulated.

TABLE 1 Comparison of Countries for Ratings of Human Capital and Innovation (2017)

\begin{tabular}{|l|c|c|}
\hline \multicolumn{1}{|c|}{ Country } & $\begin{array}{c}\text { Rating of } \\
\text { Human Capital }\end{array}$ & $\begin{array}{c}\text { Innovation } \\
\text { Rating }\end{array}$ \\
\hline Norway & 1 & 19 \\
\hline Finland & 2 & 8 \\
\hline Switzerland & 3 & 1 \\
\hline USA & 4 & 4 \\
\hline Denmark & 5 & 6 \\
\hline Germany & 6 & 9 \\
\hline New Zealand & 7 & 21 \\
\hline Sweden & 8 & 2 \\
\hline Slovenia & 9 & 32 \\
\hline Austria & 10 & 23 \\
\hline$\ldots$ & 16 & 45 \\
\hline Russia & & \\
\hline
\end{tabular}

Under the condition of effective managerial influence, the degree of involvement of employees in digitalization processes as well as their understanding of the goals, objectives and specifics of the transformation processes taking place in the company increases. This reflects the motivational characteristics of employees, whose interests and needs are gradually shifting towards more responsible work, solving difficult, interesting tasks, generating and implementing creative ideas. This forms the aspiration of each employee to feel involved in the company's business and be full-fledged, informed participants in the digital transformation process. Consequently, in the course of digital risk management, positive changes occur in the motivational structure of employees. Being consolidated within the framework of a modern self-learning organization, such changes generate new organizational knowledge, which ultimately develops the company's corporate culture and contributes to the increase in the value of its intangible assets. Thus, there is a clear relationship between the activities of workers in managing digital risks and the improvement of their human capital.

In order for positive changes in the character and level of human capital development to be preserved and consolidated, it is necessary to develop an effective model of managerial behavior that allows company not only to control this process, but also to ensure its predetermined focus) [24].

As noted above, this is especially important in the context of the increasing importance of information technologies in the work of any modern company, which is a reflection of the process of globalization and informatization of all spheres of social and economic life.

Today, in the hands of certain employees, involved in the maintenance of information resources, a huge amount of information is concentrated. It means that important information about the work of the company is obtained not only by its owners and key managers. This creates some 
additional internal risks for the company because employees can theoretically dispose of this knowledge to its detriment. Due to the specifics of information resources, events may develop in a negative scenario, even in the absence of intent on the part of employees. In this regard, risk reduction can be achieved by decomposing information, which is concentrated among key employees, as well as regulating access to technical means of working with the most important information, including its receipt, processing, storage, transfer, protection, etc.

The sequence of managerial actions to work with information and personnel who have access to it, focused on improving the human capital of the company, should be based on a diversified approach to managing employees working with information, the loss of which or falling into the hands of third parties will lead to digital risks.

The implementation of this model requires an expert evaluation, during which the likelihood of the occurrence of risk events, which may be caused by actions or inactions of its own personnel (both containing and not containing illegal intent), is determined.

The following sequence of actions is proposed:

1. To reveal and classify the information, the loss of which may form a risk for this company. The information could be classified according to its importance, relevance, types of risks associated with it, etc.

2. To calculate a probability of forming a digital risk for each of the groups of information identified within the framework of the classification. As part of this, an expert assessment of information, the loss of which can lead to risk events is carried out.

3. To determine the possible level of negative consequences of individual digital risks given the scale of their impact.

4. To select the types of information (including technical means of its storage, transfer and use) for their ranking from the standpoint of determining the greatest importance of protection.

5. To develop a program of information protection measures, including tasks, tools, resources, implementation costs, deadlines, responsible people and a system for evaluating the results obtained.

6. To implement the developed program of information protection measures.

7. To monitor the results of the program implementation with the corrective managerial impact.

The implementation of the specified sequence of actions allows management of the company to identify additional risks and problem areas in the organization of work of personnel. According to the authors, the adjustment of actions of workers in the process of eliminating the identified problems will also contribute to the improvement of the company's human capital, as this will form new benchmarks for organizational behavior in the conditions of digital risk.

This underlines the importance of managerial influence in relation to employees having access to potentially risk information or dealing with its technical support. All this work begins with the selection of personnel, but should not be limited to this stage. A necessary condition here is the formation of a team with high level of morally, materially and professionally concernment in the development of the company and its effective work. Otherwise, it will not be possible to provide a high-quality protection of information. Aside from that, the management of the company should direct attention to contacts, both formal and informal, between employees who have access to information. It is necessary to maintain a reasonable balance between the restriction of such contacts and the development of the system of intra-organizational communications, which is the key to a favorable social and psychological climate. No one doubts the fact that excessive restrictions may adversely affect the development of a company undergoing a digital transformation, because they impede the formation of a healthy, efficiently working team.

When solving problems in the field of working with digital risks, the requirements for personnel and its assessment increase. This implies the use of additional parameters in evaluating employees, both at the stage of selecting them for a job and the stage of monitoring their performance.

The assessment should be carried out for each group of workers and provide for detailing at the level of individual positions, or even separate workers. In addition, it will be envisaged the extension of the assessment, including the following gradation: intern - worker - experienced worker mentor. This, in turn, will contribute to the improvement of human capital based on mechanisms for duplicating successful patterns of organizational behavior, ensuring continuity and transferring corporate knowledge.

As a result, employees involved in digital risk management should have a conviction in the need to protect their company by countering risk events and illegal actions by third parties. In the course of targeted actions to reduce threats and minimize the possible consequences of such risks, the needs of workers involved in managing digital risks are reoriented. We can expect the gradual transition from strictly controlled execution of instructions from the manager to independent preventive actions. At the same time, the model of organizational behavior aimed at avoiding possible sanctions, punishments, fines, gives way to the achievement oriented model, the main priority of which is getting the employee better results and his development together with the company. Thereby, the most important direction of human capital improvement is being implemented.

Certainly, the described positive changes in a company that manages the risks of digitalization should be assessed in terms of their effectiveness. For assessing the effectiveness of digital risk management, a methodology to evaluate the costs of information technology can be used as a basis. This technique, proposed by the American analytical company Gartner Group, is based on the accounting of total costs for these goals. This approach, along with an assessment of the costs already incurred, makes it possible to determine the need for future costs, which allows us to more accurately calculate the company's budget for managing the risks of digitalization. 
Total costs of working with the risks of digitalization include direct and indirect costs.

The direct costs include:

- costs for purchase/development of new information tools and software and their modernization;

- costs for wages of personnel working with risks.

- costs for risk management;

- costs for the organization of work of users in a remote mode (if available);

- costs for third-party services (information outsourcing)

- costs for monitoring the work of departments and employees whose activities are associated with risks;

- costs for certification of equipment, software, personnel;

- training costs.

As part of the assessment, we can use the system analysis tools and private indicators that allow us to define additional specific indicators for their subsequent synthesis.

We can attribute to private indicators:

a) indicators characterizing the organization of the protection of the company from the effects of digital risks;

b) indicators characterizing the management of information resources used to work with risks and their negative impact;

c) indicators characterizing the protection (especially from unauthorized access) of computer equipment, information storage and data transmission channels;

d) indicators characterizing the state and effectiveness of risk management;

e) indicators characterizing the efficiency of management of employees having access to risk information.

Thanks to the detailing costs we can determine the causes of digital risks and identify areas of work to eliminate them. It provides the company's output to the specified parameters of its digital transformation. Such cost analysis can be carried out within the framework of the target financing model. It should be emphasized that these costs are closely interrelated, and in practice it is quite difficult to isolate in their total amount the share of costs directly related to digital risks.

\section{RESULTS}

During the analysis the content of the digital risk management activity and its impact on improving the human capital of a company engaged in digital transformation, the following results were obtained.

1. A relationship between the effective organization of work with personnel engaged in managing digital risks and the improvement of the company's human capital has been established. It has been determined that, in the course of digital risk management, an innovative, creative potential of employees develops, and positive changes are occurring in their motivational structure. This contributes to the development of the human capital of a company transitioning to a digital platform for business activities.

2. The sequence of managerial actions to work with information in the field of digital risks (including 7 stages) has proposed, and the areas forming the new benchmarks for the organizational behavior of risk management workers have been identified. It has been established that the implementation of this sequence of actions in the framework of the effective managerial impact contributes to the improvement of the company's human capital.

3. Based on the tendency to increase the cost for informatization of business activities, especially in the field of digital risks, the areas for evaluating the effectiveness of working with digital risks have been identified. The presented grouping of costs for working with digitalization risks allows management of the modern companies to identify the directions of work to reduce them and improve the efficiency of digital transformation processes.

\section{DISCUSSION}

The results obtained in this study confirm the earlier conclusions made by the modern theorists and practitioners of digitalization. In particular, we are talking about the fact that companies engaged in digital transformation should constantly carry out a reliable assessment of the level of protection of the company against the risks of digitalization in the context of their costs of risk management. At the same time, with all the significance of the financial and time costs for creating, implementing and maintaining a digital risk management system, the most important factor is connected with workers and their human capital. Without participation of employees, it is impossible to organize the effective use of expensive computer equipment and its adjustment to solve such complex issues as minimizing and eliminating digital risks.

In this regard, an effective organization of work with personnel, starting from the stage of its selection by categories of line workers and managers at various levels, is necessary. This is especially important for medium and small, firms, where all workers, one way or another, are in contact with each other. The positive changes taking place in the system of values, needs and motives of employees engaged in managing digital risks, take a fresh look at their role in the process of digital transformation and ensuring the company's strategic competitive advantages.

This allows us to consider the use of modern information technologies in conjunction with an effective personnel management system as the most important direction of working with digital risks in the context of globalization, both from the theoretical and practical positions. In this context, the conclusions and proposals made by the authors of this article do not contradict the existing scientific propositions and develop the theory of post-industrial development of modern business structures and the theory of human capital, considering new knowledge, skills, and creative abilities of people as a source of future income for the company and a guarantee of its effective innovative development. 


\section{CONCLUSION}

The results of the analysis and the proposals developed in the framework of the managerial impact on personnel engaged in working with the risks of digitalization prove the hypothesis formulated by the authors of this article. The theoretical concepts contained in the article as well as their justification demonstrate the consistency of the conclusions to the main trends in digital development, risk management and human capital. This allows us to conclude that the activity in a sphere of digitalization risk management has a great potential for the development of creative and innovative components of the human capital of the modern companies.

\section{REFERENCES}

[1] K. Otsuka, Y. Kudo, and N. Fuwa, "Introduction to the special issue on revisiting the role of human capital in development", Developing Economies, 2018, vol. 56, № 2, pp. 78-81.

[2] O. Iljashenko, I. Bagaeva, A. Levina. Strategy for establishment of personnel KPI at health care organization digital transformation (2019) IOP Conference Series: Materials Science and Engineering, 497 (1), № 012029.

[3] K. Kasemsap, "The fundamentals of human capital", Strategic Human Capital Development and Management in Emerging Economies, 2017, pp. 59-89.

[4] S.A. Shelkovnikov, I.G.Kuznetsova, D.A.Denisov, and O.O. Peshkova, "Enhancing the instruments of state support for the process of building human capital", Int. Journ. of Civil Engineering and Technology, 2018, vol. 9, № 8, pp. 1633-1641.

[5] B.N. Navruz-Zoda, and G.U. Shomiev, "The different approaches of human capital formation", Int. Journal of Innovative Technologies in Economy, 2017, № 5 (11), pp. 6-10.

[6] O.V. Kiselkina, A.V. Kharlamov, T.L. Kharlamova, and A.F. Vunotropidi, "The increasing of quality requirements of state regulation of economy in solving of social tasks", Social Sciences and Interdisciplinary Behavior: Proceedings of the 4th Int. congress on interdisciplinary behavior and social sciences: Kazan, Russia, 2016, pp. 425-427.

[7] O.S. Prichina, V.D. Orekhov, Y.V.Evdokimova, O.G. Kukharenko, and M.V. Kovshova, "Evolution of key factors and growth potential of human capital", Int. Journal of Innovative Technology and Exploring Engineering, 2019, vol. 8, № 7, pp. 2226-2234.

[8] Kozlov, A., Gutman, S., Rytova, E., Zaychenko, I. Human and economic factors of long-distance commuting technology: Analysis of arctic practices (2017) Advances in Intelligent Systems and Computing, 487, pp. 409-420.

[9] A.L. Lisovskii, K.B. Belovitskii, and A.A. Skomoroshchenko, "Consequences of digitalization of the Russian economy for human capital”, Qquality - Access to Success, 2018, vol. 19, № 2, pp. 15-19.
[10] S. Veltri, and A. Silvestri, "Iinvesting in human capital: an analysis of the mismatch between theoretical claim and managerial behaviour”, Int. Journ. of Knowledge-based Development, 2017, vol. 8, № 1, pp. 5-23.

[11] A.V. Kharlamov, T.L. Kharlamova, and O.S. Koroteeva, "Development of the Educational System and the Priorities of the Knowledge Economy", Vision 2020: Sustainable Economic development, Innovation Management, and Global Growth. Proceedings of the 30th Int. Business Information Management Association Conference: Madrid Spain, 2017, pp. 4270-4277.

[12] T. Iankovets, "Background of human capital development in the context of forming the economy of knowledge", Eureka: Social and Humanities, 2018, № 2, pp. 3-9.

[13] M. Vokoun, Z. Caha, J. Straková, F. Stellner, and J. Váchal, "The strategic importance of human resources management and the roles of human capital investment and education", Scientific Papers of the University of Pardubice. Series D: Faculty of Economics and Administration, 2018, vol. 25, № 42, pp. 258-268.

[14] V. Proteasa, B. Murgescu, and J. Sadlak, "Long term perspectives on higher education: student movements, human capital and expert culture", Int. Review of Social Research, 2018, vol. 8, № 1, pp. 7-12.

[15] Bril A.R., Kalinina O.V., Ilin I.V. (2017) Economic Analysis of Projects in the Improvement of the HR Management System of Enterprises // Proceedings of the 29th International Business Information Management Association Conference. Pp. 2268-2277.

[16] Ilin, I., Shirokova, S., Lepekhin, A. IT Solution concept development for tracking and analyzing the labor effectiveness of employees (2018) E3S Web of Conferences, 33, 03007.

[17] T. Nawaz T., "Human capital development in socio-economic malaise: evidence from the UK", Int. Journ. of Learning and Intellectual Capital, 2017, vol. 14, № 1, pp. 24-46.

[18] Kozlov, A., Teslya, A. (2017) Human factors for development of corporate internal social investments Portfolio. Advances in Intelligent Systems and Computing, 2017.

[19] Kankovskaya, A., Kalinina, O., Ilin, I. Economics of transport and sustainable development: Problems of high education in Russia (2018) MATEC Web of Conferences, 239, 08008.

[20] S. Ashby, A. Phippen, "Managing digital risk", Peer reviewed by Hayley Henderson at Northampton University, 2015, p. 49.

[21] V.N. Trenev, "Knowledge management in human capital development in the context of the digital economy", Int. Journ. of Engineering and Technology(UAE), 2018, vol. 7, № 3, pp. 108-112.

[22] Human Capital Index 2017, https://nonews.co/directory/lists/ countries/human-capital (accessed date: 22.05. 2019).

[23] INSEAD, WIPO, Cornell University: The Global Innovation Index 2017, https://gtmarket.ru/ratings/global-innovation-index/info (accessed date: 15.05. 2019).

[24] J. Kalkowska, and A.V. Kozlov, "Decision making process for the knowledge-based enterprise: fuzzy sets theory application to strategic management", Advances in intelligent systems and computing, 2016, vol. 431 , pp. $163-174$. 